\title{
Mechanical performance of biodegradable hemp shivs and corn starch-based biocomposite boards
}

\author{
Arūnas Kremensas ${ }^{1}$, Agnè Kairyte ${ }^{2}$, Saulius Vaitkus ${ }^{3}$, Sigitas Vejelis ${ }^{4}$, \\ Giedrius Balčiūnas ${ }^{5}$, Anna Strąkowska ${ }^{6}$, Sylwia Członka ${ }^{7}$ \\ 1, 2, 3, 4, 5 Laboratory of Thermal Insulating Materials and Acoustics, Institute of Building Materials, \\ Faculty of Civil Engineering, Vilnius Gediminas Technical University, Vilnius, Lithuania \\ ${ }^{6,7}$ Institute of Polymer \& Dye Technology, Lodz University of Technology, Lodz, Poland
}

\section{E-mail: ${ }^{2}$ agne.kairyte@vgtu.lt (correspondingauthor)}

\begin{abstract}
For the production of traditional building materials, excavated natural resources are used. The production process of such materials requires high-energy demands, wherefore, high amounts of $\mathrm{CO}_{2}$ gases, which have a great impact on climate change, are emitted. Only a small part of such materials is effectively recycled and reused. Generally, they are transported to landfills, which rapidly expand and may pollute the soil, groundwater and air. Currently, a great attention is paid to the production of novel building materials. The aim is to use as less excavated materials as possible and replace them by natural renewable resources. Therefore, the recycling and utilisation at the end of life cycle of such materials would be easier and generation of waste would reduce. This way, the efforts of switching to circular economy are being put. One of the approaches - wider application of vegetable-based raw materials (cultivated and uncultivated agricultural plants). The usage of fibre hemp shives (HS) as an aggregate and corn stach (CS) as a binding material allows development of biocomposite boards (WPCs) which could contribute to the solution of the before mentioned problems.

Bio-sourced materials combined with a polymer matrix offer an interesting alternative to traditional building materials. To contribute to their wider acceptance and application, an investigation into the use of wood-polymer composite boards is presented. In this study, biocomposite boards for the building industry are reported. WPCa are fabricated using a dry incorporation method of corn starch and HS treatment with water at $100{ }^{\circ} \mathrm{C}$. The amount of $\mathrm{CS}$ and the size of the HS fraction are evaluated by means of compressive, bending and tensile strength, as well as microstructure. The results show that the rational amount of CS, independently on HS fraction, is $10 \mathrm{wt} . \%$. The obtained WPCs have compressive stress at $10 \%$ of deformation in the range of (2.4-3.0) MPa, bending of (4.4-6.3) MPa and tensile strength of (0.23$0.45) \mathrm{MPa}$. Additionally, the microstructural analysis shows that $10 \mathrm{wt} . \%$ of CS forms a sufficient amount of contact zones that strengthen the final product. The obtained average density $\left(\sim 319-408 \mathrm{~kg} / \mathrm{m}^{3}\right)$ indicate that, according to European normative document EN 316, WPCs can be classified as softboards and used as self-bearing structural material for building industry. Based on the requirements, WPCs can be applied in dry and humid conditions for the internal and external uses without loading (EN 622-4, section 4.2) or as load-bearing boards in dry and humid conditions for instantaneous or short-term load duration (EN 622-4, section 4.3).
\end{abstract}

Keywords: biocomposite boards; corn starch; hemp shivs; mechanical performance; biodegrability.

\section{Introduction}

Nowadays, there is a great need to use plant particles as building material in construction. It is because sustainable development has become a subject of major attention in international and national organizations, in developed and developing countries. It involves the development of methods and techniques guiding the use, recycling and replacement of natural resources and the upholding of the earth's productivity. To build sustainable and affordable building it is needed to design efficient building materials (thermal insulating, structural and sound absorbing) with lower environmental impact especially in regard to the carbon footprint (Le, Gacoin, Li, Mai, \& Wakil, 2015).

Therefore, the use of renewable resources such as HS is of great importance. HS are generally very porous with low density tending to absorb large amounts of water. Previous studies have reported that HS not only has higher water absorption rate but also absorb high amounts of water in the very first minutes compared to different plant materials (Hussain et al., 2018; Bourdot et al., 2017). Moreover, the presence of cellulose, hemicellulose and lignin in bio-based materials contributes to the presence of hydroxyl groups in their structure. This leads to certain disadvantages of using

(C) 2019 Authors. Published by VGTU Press. This is an open-access article distributed under the terms of the Creative Commons Attribution (http://creativecommons.org/licenses/by/4.0/) License, which permits unrestricted use, distribution, and reproduction in any medium, provided the original author and source are credited. 
bio-based materials making them incompatible with hydrophobic thermoset/thermoplastic polymers (Gassan, Gutowski, \& Bledzki, 2000). Therefore, additional preparation and treatment of particles and fibres surfaces are necessary. Most of the researchers used maleic anhydride grafted polypropylene (Yang, Qiao, \& Wolcott, 2010; Zhu, Cao, Wang, Liu, \& Zhao, 2014; Bütün, Sauerbier, Militz, \& Mai, 2019) as compatibilizer in polypropylene/wood-based composites. Their studies reported that maleic anhydride can improve the mechanical performance of composites as interfacial adhesion between wood aggregate and polymer matrix is improved. It has also been reported that presence of less than $1 \mathrm{wt} \%$ maleic anhydryde can produce sufficient increase in tensile strength. Additionaly, scientists Haque et al. (2019) have used pulverization with and without water. Higher melt-viscosity of pulverised wood flour reinforced polypropylene composites indicated more roughness on particle surfaces and higher interfacial interaction between aggregate and matrix. Further pulverization of wood flour also affected to the tensile strength values of composites. The tensile strength of the processed composites with $25 \mathrm{wt} \%$ of wood flour were found in the range of 39-43 MPa. Another implemented method for the improvement of adhesion strength between wood aggregate and thermoplastic matrix is to use hydrogen peroxide (Dimitriou, Hale, \& Spear, 2016, 2018). The study showed that as $\mathrm{pH}$ increased from 7.5 to 8.5 the reaction (in the presence of $\mathrm{NaOH}$ ) of wood and hydroperoxy anions has a mildly beneficial effect, and the corresponding increase in surface energy was sufficient to induce additional adhesion. Moreover, authors Li, Xiao, Morrell, Zhou, and Du (2017) have used a pectinase pre-treatment in order to release individual shivs fibers allowing them to become more evenly distributed in a composite, resulting in a more uniform material with improved physical and mechanical properties of HS/polypropylene composites and compared them with silane coupling agents treated HS-based composites. These actions increase shivs' surface area which resulted in and improved shivs/polymer interaction with a tensile strength from $16.9 \mathrm{MPa}$ to $22.9 \mathrm{MPa}$ at $0-120 \mathrm{~min}$ pectinase treatment and from $21.7 \mathrm{MPa}$ to 22.9 MPa at silane coupling agent content of $1-5 \%$.

However, polypropylene is non-renewable feedstock and in order to increase eco-friendliness of the final products, it is important to use ecological binding materials as well. Therefore, biodegradable thermoplastic starches as binding materials are a great alternative for the preparation of environmentally friendly biocomposite boards. As hemp has a chemical composition similar to wood (Stevulova \& Schwarzova, 2014), albeit with greater hydrophobicity and counterintuitively, a lower adsorption potential in spite of its cellular microstructure (Khan et al., 2018), it is more expedient to use HS as an aggregate and biodegradable CS as a binding material for the production of wood-plastic composites (WPCs). Sandrine, Isabelle, Hoang, and Chadi (2015) have used NaOH pre-treatment before the treatment of HS with silane coupling agent. The study showed that alkaline treatment with $1 \%$ of $\mathrm{NaOH}$ removes amorphous compound on the surface of HS in the first step and secondly a silane coupling agent creates a cross-linked network between the starch-based matrix and HS leading to an improved compressive and bending strength from $0.4 \mathrm{MPa}$ to $0.8 \mathrm{MPa}$ and from $0.15 \mathrm{MPa}$ to $0.25 \mathrm{MPa}$, respectively. It is worth to note that chemical treatment is efficient but can be replaced by a more simple and environmentally friendly surface activation method, i. e. aggregate treatment with hot water. There are only few studies (Santos et al., 2018) on the impact of hot water-treated aggregates on the final properties of WPCs. Some of them state that The physical treatments like enzyme, electron beam radiation and hot water treatments deteriorate the flexural properties of composites (Venkateshwaran, Perumal, \& Arunsundaranayagam, 2013; Sood \& Dwivedi, 2018). This is because of deterioration of fibers due to over xtraction of extractives of fibers. Therefore, the aim of this study is to prove and evaluate the positive effect of hot water treatment on surface activation and mechanical performance as well as microstructure of fully ecological WPCs produced from $10 \mathrm{wt} . \% \mathrm{of}$ corn starch binder and different fractions of HS.

\section{Materials and methods}

\section{Raw materials}

For the preparation of WPCs, fibre HS aggregate arising from a hemp fibre separation process was used. The microstructure of HS shiv is presented in Figure 1. The HS fractions were chosen to be 2.5/5, 5/10, 10/20 and $2.5 / 20 \mathrm{~mm}$. Additionally, the shredded fraction obtained from milling a 2.5/20 $\mathrm{mm}$ fraction was used. As a binder, CS was chosen and used at amount of 10 wt.\%.

\section{Preparation of WPCs}

All fractions were treated with $100{ }^{\circ} \mathrm{C}$ water and left for $2 \mathrm{~h}$, after which they were drained for 10 min in order to eliminate an excess of water. Into water treated HS, CS was dosed through a $0.63 \mathrm{~mm}$ sieve.

WPCs were formed using a metal mould. Furthermore, the forming mixture is distributed through the whole frame. Then, the mixture is trampled down with wooden scantling in order to obtain the initial form. After that, the upper part of the mould is added onto the bottom part and both of them are screwed together. The whole setup is then put on the stand, and a hydraulic jack is set on the upper part of the mould. The mixture is compressed up to 40 vol.\% and thermally treated at $160{ }^{\circ} \mathrm{C}$ for 6 hours. 

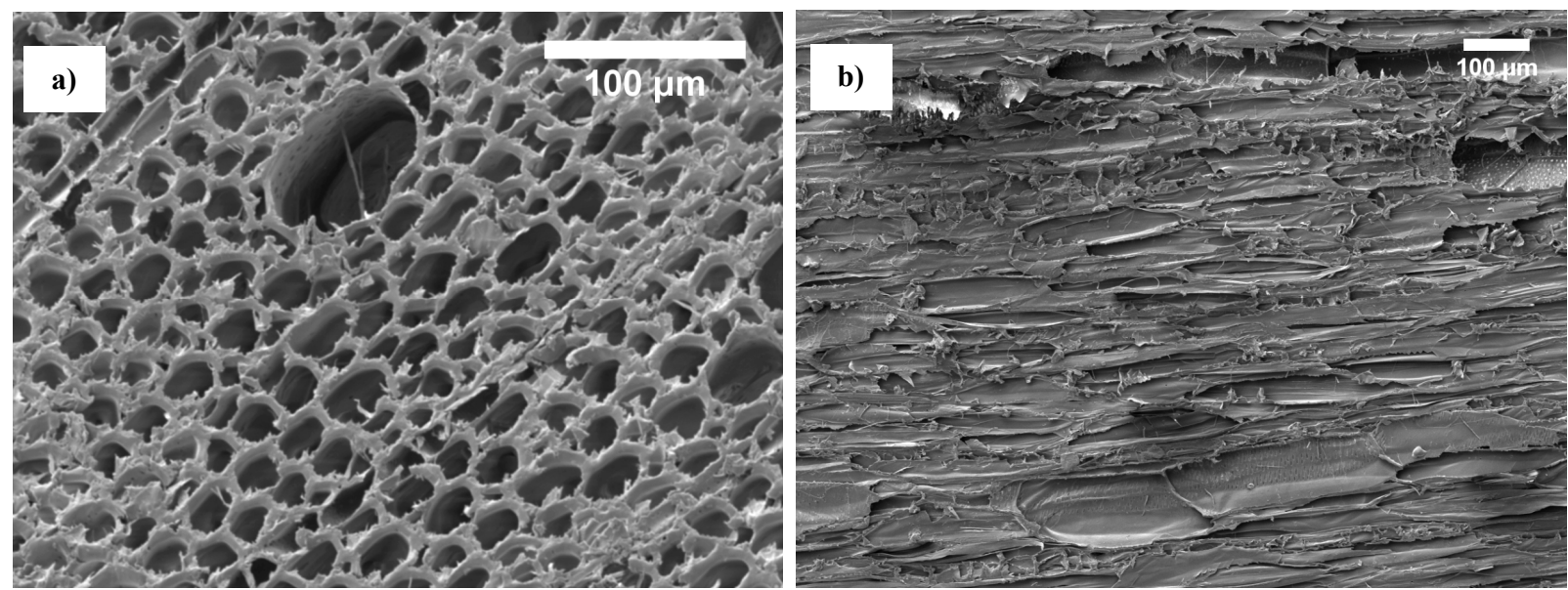

Figure 1. Microstructure images of HS: a) perpendicularly to the direction of stem growth; b) along the direction of stem growth

\section{Test methods}

Compressive stress at $10 \%$ of deformation was tested according to the EN 826 method using a computerised machine HOUNSFIELD H10KS (Figure 2a). Three specimens for each composition with a size of $50 \times 50 \times \mathrm{d} \mathrm{mm}(\mathrm{d}-$ thickness of specimen) were prepared. Before the test, specimens were conditioned for not less than $6 \mathrm{~h}$ at $(23 \pm 5){ }^{\circ} \mathrm{C}$.

The bending strength of the WPCs was determined in accordance with the EN 310 method. For the test, equipment consisting of two parallel cylinder supports, which have a length greater than the side of a specimen, and diameters of $(15 \pm 0.5)$ and $(30 \pm 0.5) \mathrm{mm}$, were used (Figure $2 \mathrm{~b})$. The test was conducted using the same computerised machine as for compressive stress determination for three specimens with a size of $(20 \cdot d+50) \times 50 \times d \mathrm{~mm}$. Before the test, specimens were conditioned at $(20 \pm 2){ }^{\circ} \mathrm{C}$ and $(65 \pm 5) \%$ relative air humidity until constant mass was achieved.

The tensile strength perpendicular to the specimen surface was tested based on the EN 319 method. The test was conducted using the computerised machine used for compressive stress and bending strength determination (Figure 2c). Three specimens for each composition with a size of $50 \times 50 \times \mathrm{d} \mathrm{mm}$ were prepared. Before the test, specimens were conditioned at $(20 \pm 2){ }^{\circ} \mathrm{C}$ and $(65 \pm 5) \%$ relative air humidity conditions until constant mass was achieved.
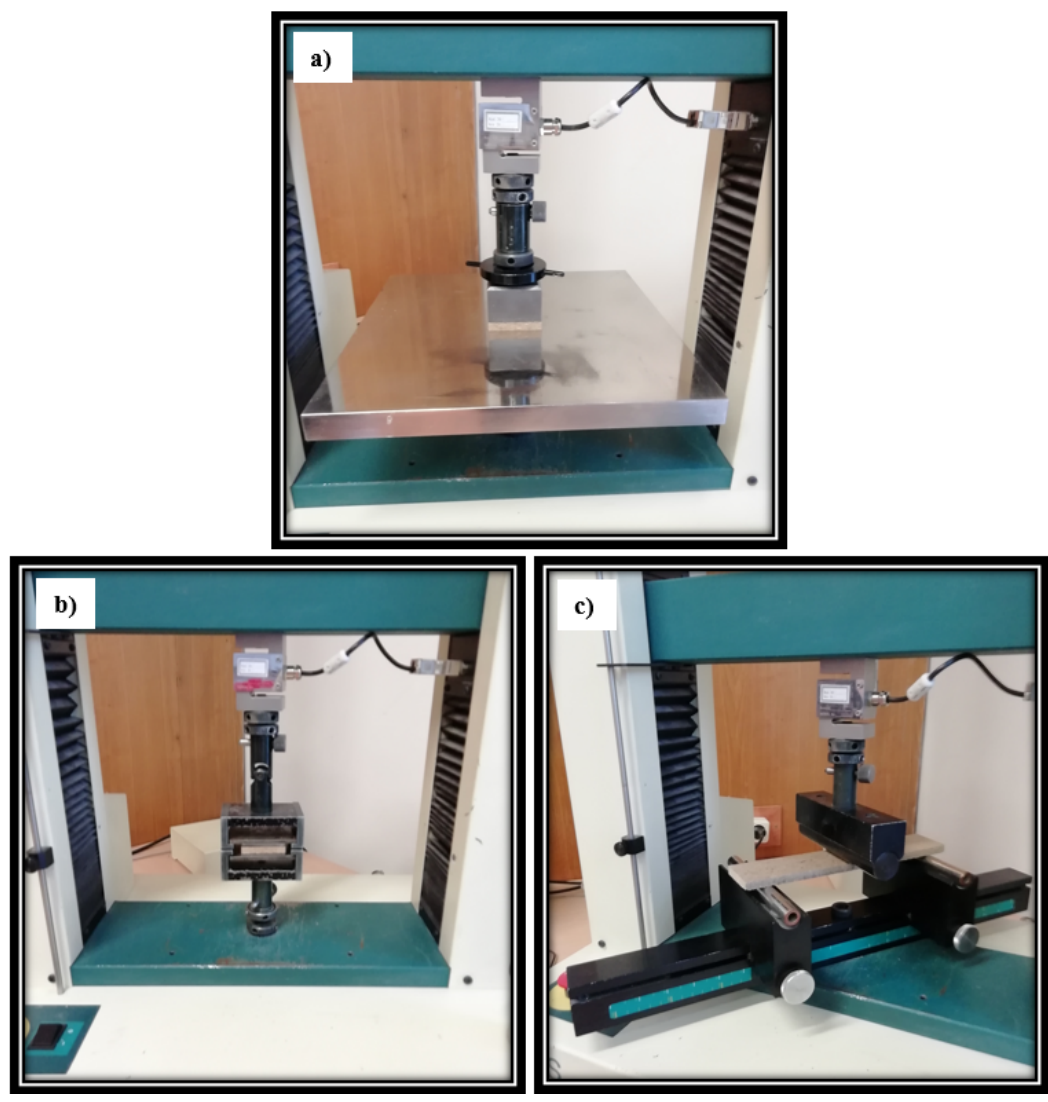

Figure 2. Test setup of a) compression; b) tension and c) bending 
The density was determined according to EN 1602 for specimens which size was the same as for mechanical properties testing. The structure of the WPC was studied using scanning electron microscopy (SEM) with a JEOL SM7600F. Before the SEM analysis, the WPCs were sputter coated with a thin gold layer under vacuum using a QUORUM Q150R ES.

\section{Results and discussion}

The apparent density is one of the most important parameters determining the stability of the final products in terms of strength and durability. Therefore, it is of great importance to determine such parameter for WPCs. As can be seen from Table 1, the average values of apparent density of all fractions-based WPCs range within the margin of error. However, the greatest value, i. e. $381 \mathrm{~kg} / \mathrm{m}^{3}$, for shredded shivs-based WPC is obtained due to a better densification during compresion of smaller particles in shredded fraction. Almost twice lower density of $\sim 2.5 / 20 \mathrm{~mm}$ HS and wheat starch-based WPCs was obtained by Le et al. (2014). The differences may be attributed to the fact that the later WPCs were not loaded and the used starch binder was treated differently compared to a current study where the loading up to 40 vol. $\%$ was used.

Table 1. Average density results for WPCs with different shivs fractions and $10 \% \mathrm{CS}$

\begin{tabular}{|l|c|c|c|c|c|}
\hline \multirow{2}{*}{ Parameter } & \multicolumn{5}{|c|}{ Shivs fraction, $\mathrm{mm}$} \\
\cline { 2 - 6 } & $5 / 10$ & $10 / 20$ & $2.5 / 20$ & $2.5 / 5$ & Shredded shivs \\
\hline Average density, $\mathrm{kg} / \mathrm{m}^{3}$ & 377 & 373 & 364 & 375 & 381 \\
\hline Standard deviation, $\mathrm{kg} / \mathrm{m}^{3}$ & 20.3 & 19.6 & 19.7 & 14.2 & 14.7 \\
\hline
\end{tabular}

Mechanical performance is important for those structures which are subject to short-term or long-term loading. Therefore, it is necessary to evaluate the change in the main mechanical properties - compressive stress at $10 \%$ deformation, bending and tensile strength of WPCs obtained using different HS fractions. Contrary to the obtained results for WPC with shredded HS, WPCs from $5 / 10 \mathrm{~mm}, 10 / 20 \mathrm{~mm}, 2.5 / 20 \mathrm{~mm}$ and 2.5/5 mm HS fractions are characterised by the lowest compressive stress values (Figure 3a). The parameter, when $10 \mathrm{wt} \%$ of CS is used, averagely varies from $\sim 2.3 \mathrm{MPa}$ to $\sim 2.7 \mathrm{MPa}$. The obtained values are similar to the ones presented by Stevulova, Cigasova, Schwarzova, Sicakova, and Junak (2018) who have additionally treated $\mathrm{HS}$ with $\mathrm{NaOH}, \mathrm{Ca}(\mathrm{OH})_{2}$ and ethylenediamintetracetic acid. It means that the same or even better values may be obtained when the aggregate is hoter watertreated and no chemicals are used.

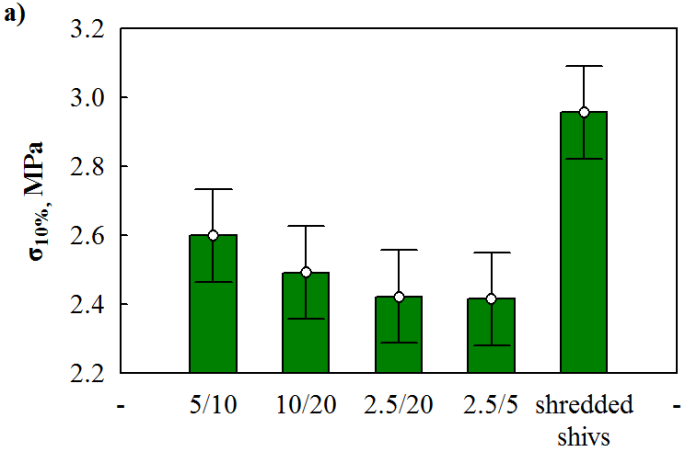

Shivs fraction, $\mathbf{m m}$

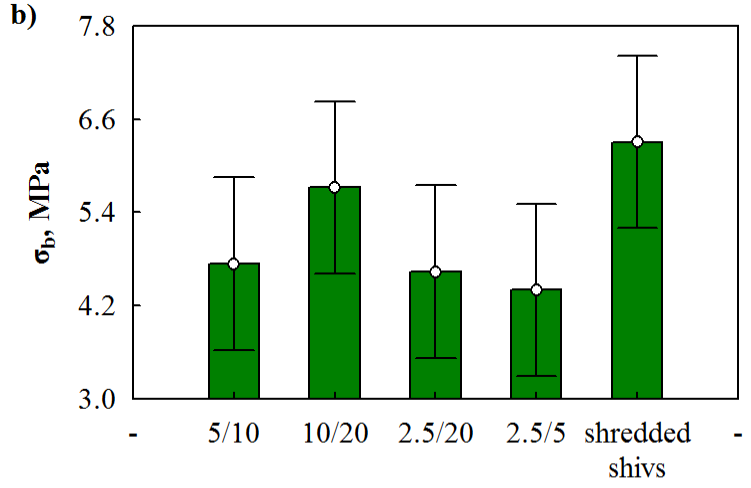

Shivs fraction, mm

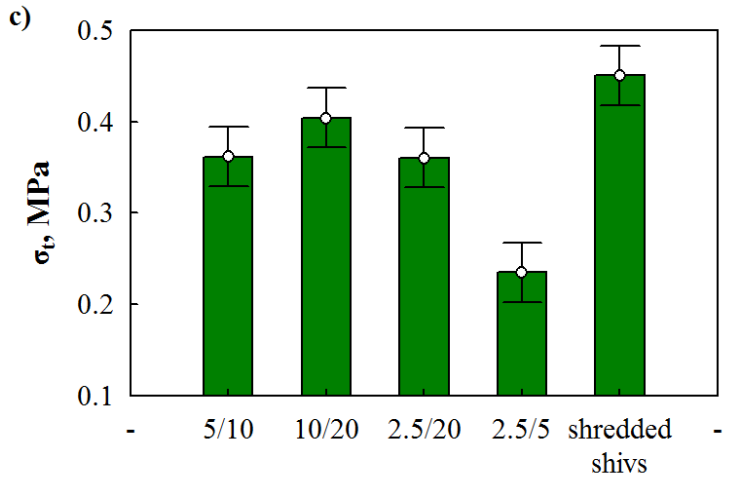

Shivs fractions, mm

Figure 3. Mechanical performance of WPCs: a) compressive stress at 10\% deformation; b) bending strength; c) tensile strength 
Additionally, Figure 3b shows that the highest bending strength is obtained for WPC with shredded HS fraction. It can be noted that it is by $\sim 33 \%, \sim 10 \%, \sim 36 \%$ and $\sim 43 \%$ increased compared to, respectively, $5 / 10 \mathrm{~mm}, 10 / 20 \mathrm{~mm}$, 2.5/20 mm, 2.5/5 mm fractions. In SEM images (Figure 4) of the WPC with a binder, it is noted that the HS are fully enclosed by the CS matrix and a considerable adhesion occurs in the interface region between the two components. The action of hot water treatment causes defibrillation of HS and a better interfacial adhesion is obtained.
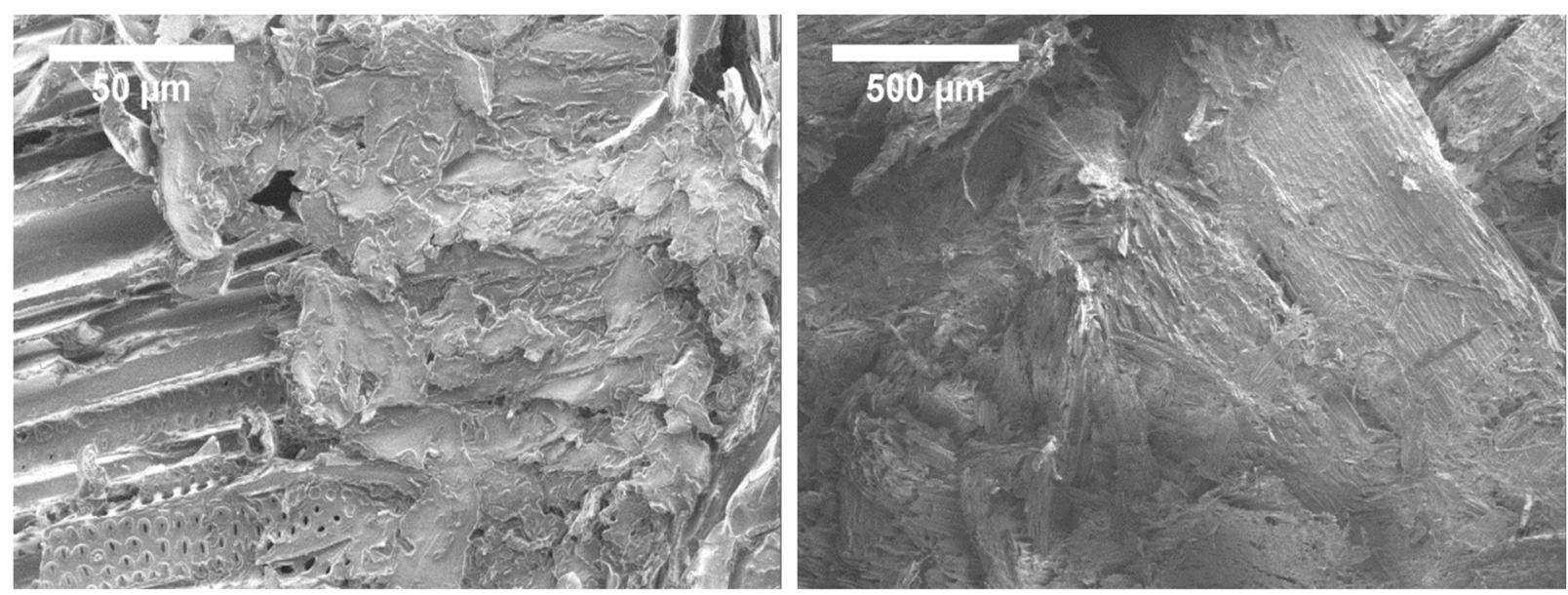

Figure 4. Microstructure of WPC after mechanical impact: a) WPC without CS; b) WPC with CS

Comparing the results of WPCs from all fractions HS and $10 \mathrm{wt} . \%$ of CS, it is determined that tensile strength for shredded HS-based WPC is by $\sim 2.9$ times higher than for $2.5 / 5 \mathrm{~mm}$-based WPC (Figure 3c). The addition of $10 \mathrm{wt} . \%$ of CS, tensile strength of all HS fractions WPCs reaches (0.20-0.39) MPa. Because HS have porous structure, part of CS particles can penetrate and fill the pores and form a sufficient mechanical bonding with another part of CS which enhance the interface between HS and CS.

\section{Conclusions}

WPC with shredded HS aggregate and $10 \mathrm{wt} . \% \mathrm{CS}$ are characterised by the highest mechanical properties. Independently on HS fraction, such WPCs have: compressive stress at 10\% of deformation varies from 2.4 to $3.0 \mathrm{MPa}$, bending strength - from 4.4 MPa to $6.3 \mathrm{MPa}$ and tensile strength - from $0.23 \mathrm{MPa}$ to $0.45 \mathrm{MPa}$. The obtained results indicate that WPC can be used as self-bearing structural material for building industry. Based on the mechanical performance, it is expedient to produce WPC from shredded HS and $10 \mathrm{wt} . \%$ of CS.

Between shredded HS particles, more contact zones form and, under the thermal treatment at $160{ }^{\circ} \mathrm{C}$, bonds form from CS. Consequently, they strengthen the zones between aggregate particles and form structure, which determines the better mechanical performance compared to WPC with non-shredded HS.

Based on the requirements, WPCs can be applied in dry and humid conditions for the internal and external uses without loading (EN 622-4, section 4.2) or as load-bearing boards in dry and humid conditions for instantaneous or short-term load duration (EN 622-4, section 4.3).

\section{References}

Bourdot, A., Moussa, T., Gacoin, A., Maalouf, C., Vazquez, P., Thomachot-Schneider, C., ..., \& Polidori, G. (2017). Characterization of hemp-based agro-material: Influence of starch ratio and hemp shive size on physical, mechanical, and hygrothermal properties. Energy and Buildings, 153, 501-512. https://doi.org/10.1016/j.enbuild.2017.08.022

Bütün, F. Y., Sauerbier, P., Militz, H., \& Mai, C. (2019). The effect of fibreboard (MDF) disintegration technique on wood polymer composites (WPC) produced with recovered wood particles. Composites Part A, 118, 312-316. https://doi.org/10.1016/j.compositesa.2019.01.006

Dimitriou, A., Hale, M. D., \& Spear, M. J. (2016). The effect of four methods of surface activation for improved adhesion of wood polymer composites (WPCs). International Journal of Adhesion and Adhesives, 68, 188-194. https://doi.org/10.1016/j.ijadhadh.2016.03.003

Dimitriou, A., Hale, M. D., \& Spear, M. J. (2018). The effect of pH on surface activation of wood polymer composites (WPCs) with hydrogen peroxide for improved adhesion. International Journal of Adhesion and Adhesives, 85, 44-57. https://doi.org/10.1016/j.ijadhadh.2018.05.012

Gassan, J., Gutowski, V. S., \& Bledzki, A. K. (2000). About the surface characteristics of natural fibres. Macromolecular Materials and Engineering, 283(1), 132-139. https://doi.org/10.1002/1439-2054(20001101)283:1<132::AID-MAME132>3.0.CO;2-B 
Haque, M. M.-Ul, Goda, K., Ito, H., Ogoe, S., Okamot, M., Ema, T., ..., \& Nogami, H. (2019). Melt-viscosity and mechanical behavior of polypropylene (PP)/wood flour composites: Effect of pulverization of wood flour with and without treatment. Advanced Industrial and Engineering Polymer Research, 2(1), 42-50. https://doi.org/10.1016/j.aiepr.2018.11.001

Hussain, A., Calabria-Holley, J., Schorr, D., Jiang, Y., Lawrence, M., \& Blanchet, P. (2018). Hydrophobicity of hemp shiv treated with sol-gel coatings. Applied Surface Science, 434, 850-860. https://doi.org/10.1016/j.apsusc.2017.10.210

Khan, B. A., Na, H., Chevali, V., Warner, P., Zhu, J., \& Wang, H. (2018). Glycidyl methacrylate-compatibilized poly(lactic acid)/hemp hurd biocomposites: Processing, crystallization, and thermo-mechanical response. Journal of Materials Science and Technology, 34(2), 387-397. https://doi.org/10.1016/j.jmst.2017.03.004

Le, A. T., Gacoin, A., Li, A., Mai, T. H., Rebay, M., \& Delmas, Y. (2014). Experimental investigation on the mechanical performance of starch-hemp composite materials. Construction and Building Materials, 61, 106-113. https://doi.org/10.1016/j.conbuildmat.2014.01.084

Le, A. T., Gacoin, A., Li, A., Mai, T. H., \& Wakil, N. El. (2015). Influence of various starch/hemp mixtures on mechanical and acoustical behavior of starch-hemp composite materials. Composites Part B, 75, 201-211. https://doi.org/10.1016/j.compositesb.2015.01.038

Li, X., Xiao, R., Morrell, J. J., Zhou, X., \& Du, G. (2017). Improving the performance of hemp hurd/polypropylene composites using pectinase pre-treatments. Industrial Crops and Products, 97, 465-468. https://doi.org/10.1016/j.indcrop.2016.12.061

Sandrine, U. B., Isabelle, V., Hoang, M. T., \& Chadi, M. (2015). Influence of chemical modification of hemp-starch concrete. Construction and Building Materials, 81, 208-215. https://doi.org/10.1016/j.conbuildmat.2015.02.045

Santos, E. B. C., Moreno, C. G., Barros, J. J. P., Araújo de Moura, D., Fim, F. C., Ries, A., ..., \& Balbino da Silva, L. (2018). Effect of alkaline and hot water treatments on the structure and morphology of piassava fibers. Materials Research, 21(2), 1-11. https://doi.org/10.1590/1980-5373-mr-2017-0365

Sood, M., \& Dwivedi, G. (2018). Effect of fiber treatment on flexural properties on natural fiber reinforced composites: A review. Egyptian Journal of Petroleum, 27(4), 775-783. https://doi.org/10.1016/j.ejpe.2017.11.005

Stevulova, N., Cigasova, J., Schwarzova, I., Sicakova, A., \& Junak, J. (2018). Sustainable bio-aggregate-based composites containing hemp hurds and alternative binder. Buildings, 8(25), 1-14. https://doi.org/10.3390/buildings8020025

Stevulova, N., \& Schwarzova, I. (2014). Changes in the properties of composites caused by chemical treatment of hemp hurds. International Journal of Environmental and Ecological Engineering, 8(5), 443-447. doi.org/10.5281/zenodo.1092964

Venkateshwaran, N., Perumal, A. E., \& Arunsundaranayagam, D. (2013). Fiber surface treatment and its effect on mechanical and visco-elastic behavior of banana/epoxy composite. Materials and Design, 47, 151-159. https://doi.org/10.1016/j.matdes.2012.12.001

Yang, H.-S., Qiao, P., \& Wolcott, M. P. (2010). Fatigue characterization and reliability analysis of wood flour filled polypropylene composites. Polymer Composites, 31(4), 553-560. https://doi.org/10.1002/pc.20848

Zhu, L., Cao, J., Wang, Y., Liu, R., \& Zhao, G. (2014). Effect of MAPP on interfacial compatibility of wood flour/polypropylene composite evaluated with dialectric approach. Polymer Composites, 35(3), 489-494. https://doi.org/10.1002/pc.22686 